\title{
Lexical and grammatical transformations from the Chinese language perspective: universal approach
}

\author{
Natalia Shchurik ${ }^{*}$, Tatiana Shishmareva, Elena Weber and Julia Dundik. \\ ${ }^{1}$ Irkutsk State University, 664003 Irkutsk, Russia
}

\begin{abstract}
The paper describes different approaches to lexical and grammatical transformations in modern translation studies. It sheds new light on traditional approaching Chinese translation studies. Using experience of teaching students studying the French and the German languages the authors provide several reasons for proposing the Russian traditional classifications of lexical and grammatical transformations into courses of translation from Chinese practical. According to this approach, there are such types of transformations as lexical and grammatical, as well as complex (or mixed) ones. Such consistent and universal perspective is aimed to help students to understand grammatical and lexical asymmetry of the source and the target languages and it can be of great use in writing research papers.
\end{abstract}

\section{Introduction}

In the Chinese linguistic tradition the first profound attempts to find methods to translate from the original language to the target language took place in the beginning of our era. They are associated with the ideological factor of the introduction of the Buddhist culture to China, which had a great influence on the development of the written form of the Chinese language. It was at that time when the first problems directly related to the translation of the cultural realia of another culture and some of its terms emerged.

These problems were primarily caused by the typological characteristics of Sanskrit and Ancient Chinese.

The Ancient Indian language abounded in multisyllabic words was characterized by the developed morphology and was a typical representative of inflexional languages, whereas Old Chinese unlike Sanskrit had poor morphology, the developed system of functional words, isolating syntax; the lexical structure of the language had mainly single-syllable units.

The theoretical principals of translation studies have been developing very gradually. It was a very complicated process.

For example, in order to render the Buddhist philosophical terminology, the terms of Chinese traditional philosophy were more often used.

Even the basic concept of dharma was translated literally by the Chinese word 法 "law".

Due to the difference in the syllabic structure of Sanskrit and Chinese the proper names were borrowed in a distorted form and entered the Chinese language in truncated form, and several methods of translation were used to achieve this: transcription, calque translation, semantic equivalent and combination of several methods of translation.

For example, the proper name Buddha is translated as Foto 佛驮 in the written language and in the truncated form Fo 佛 in the spoken language.

Three and four-syllable proper names were truncated to two-syllable words: Ananda 阿南 (Anan).

Senjia 僧伽 means "monk".

Such cosmological concept as jumbudvipa - the continent where the Buddhist countries are located - was translated by transcription of the proper geographical name jumbzhanbu 瞻部 and by rendering the word dvipa "continent" by the Chinese equivalent 洲 zhou "continent".

In those cases when it was impossible to find a Chinese single-syllable word for the translation of the term, two-syllable words were created: Samsara - 轮回 literally "rotation" [1].

This was a crucial moment for the development of translation studies in China. These methods of translation were used repeatedly later in contacts with Western European culture.

Although the first steps to understand the nature of translation were taken in the first century AD, it should be noted that the general theoretical problems of translation from Chinese to the European languages, and 
from the European languages to Chinese, couldn't be applied to practical translation.

Throughout the history of the Russian sinological tradition, the issues of the theory and practice of translation have been considered separately. Scientists have dealt mainly with the development of narrowly focused aspects, such as military and political translation, social and political translation, translation of ancient Chinese texts.

The most famous works belong to L.G Abrakhimov [2], L.A. Radus [2], V.V. Tkachuk [2], I.V. Voytsekhovich [3, 4], A.F. Kondrashevsky [3, 4], A.A. Voytsekhovich [4], I.D. Klenin [5], V.F. Shchichko [5], A.V. Ankin [6], I.G. Khripunov [6], A.V. Boyarkina [7], V.I. Voronov [7], K.S. Knyazev [7], R.A. Polonchuk [8], V. Volkov [9], V.V. Kruglov [10], E.A. Khamaeva [11], T.E. Shishmareva [11], E. V. Kremnyov [11], M.I. Varakina [12], O.M. Gotlib [12, 13], Yu. G. Lemeshko $[14,15]$.

And there not many researchers in the theory of translation. This field is represented only by V.A. Rostovtsev [16], V.F. Shchichko [17, 18], G. Yu. Yakovlev [18].

\section{Methods and material}

This study uses different data collection methods such as an analytical method, observation and interpretation, methods of critical discourse analysis and a comparative method. This approach helps to raise a question about the necessity of a development universal approach to grammatical and lexical transformations study.

The material for case study analysis is taken from students' papers.

\section{Results and discussion}

General issues of translation of the theoretical course cover different approaches to grammatical and lexical transformations. Students usually study to compare author's theories to find out the same and the difference. Studying different interpretations help students to understand and analyze lexical and grammatical problems of translation. Moreover, it provides universal theoretical basis for future diploma thesis research. Then sophomore students start studying the same question in the Chinese language.

In comparison with Russian translation school in Chinese translation studies, it is hardly possible to find more than two works dedicated to this problem. Students of Irkutsk State University usually apply to the book of V.F. Shchichko [17] in their practical courses of Chinese. This author deeply describes the problems of translation paying special attention to linguo-cultural differences of Chinese and Russian. It is very important because translation is a part of culture and vice versa. Moreover, a translator must be a link between the mythologems of source and target cultures [19].

However, a number of questions regarding this book remain to be addressed. For example, there is no difference between translation methods and transformations. The fourth chapter is called "Methods of Translation". Its content represents heterogeneous approach: there are homonym translation problems, omission, antonymic translation, generalization and so on. The chapter is not structured logically. Students begin mixing transformations and lexical and grammatical problems of translation. Moreover, there is a paragraph called "Syntactic Transformations". In spite of the fact that syntax is a part of Grammar, such approach leads to misunderstanding of basic theoretical principals.

The practical course of translation for bachelors should be transparent and clear. The master programs can be more complicated covering different scholars and theories. We suggest that it is necessary to apply to the historical perspective of this question.

So, the word "transformation" in Latin means "the change of the form", the verb "transformare" means "to transform", to change, and also "to translate".

The term "transformation" came to modern translation studies from generative linguistics, where it was presented as a method of generating secondary language structures which consisted in regular transformation of basic (nuclear) structures into surface ones.

Different interpretation of the term is connected with the fact that the term "transformation" in the modern theory of translation is associated with three different concepts:

- the relation between language or speech units of the compared languages;

- linguistic or inter-linguistic operations;

- the translation process as a whole.

One of the first definitions of translation transformation was given by L.S. Barkhudarov and it is considered to be the most accurate: "a variety of interlinguistic transformations performed by the translator in order to achieve the best possible exactness in rendering all the information contained in the source text, with strict compliance with the rules of the target text". The text itself remains unchanged, but along with it and based on it another text in another language is created which is called a "translation". Translation itself is nothing but an interlingual type of transformation" [20].

The approach to the definition of "translation transformation" differs among different linguists. The issue of translation transformations has received attention from such Russian translatologists as Y.I. Retzker [21], A.D. Schweitzer [22], L.K. Latyshev [23, 24], T.A. Kazakova [25], V. G Gak and E. B. Roisenblit [26], N.K. Garbovsky [27] and others.

Due to its logicality, consistency, and ease of integration into the educational process, V.N. Komissarov's classification has gained the greatest popularity in domestic translation schools.

According to his approach, there are such types of transformations as lexical and grammatical, as well as complex (or mixed) ones.

V.N. Komissarov refers to the list of lexical transformations, such as transliteration, translation transcription, calque translation, some lexical-semantic 
replacements, for example, modulation, concretization and generalization.

The group of grammatical transformations includes word-for-word translation (or syntactic assimilation), grammatical replacements (replacement of sentence parts, word forms, parts of speech), transposition, sentence integration and partitioning of sentences.

Complex transformations can also be called lexicalgrammatical transformations. These include explication (in other words, descriptive translation), antonymic translation, and compensation. Let us consider each type of transformation separately.

Transcription and transliteration are the methods of translation the lexical units of the original language by recreating their form with the help of the letters of the target language.

Transcription reproduces the sound form of a foreign word, while transliteration reproduces its grammatical form (letter composition).

Calque translation is a method of translation of lexical units of the original language by replacing its parts-morphemes or words (in fixed expressions) - by their lexical correspondences in the target language.

Calque translation allows creating a new word or a fixed expression in the target language, copying the structure of the original unit.

Modulation (semantic, logical development) is a lexical-semantic transformation, in which the replacement of a word or phrase in the source language by a unit of the target language logically derived from the original unit is observed.

Concretization is a lexico-semantic transformation, in which of a word or a phrase of the source language with a broader subject-logical meaning is replaced by a word or phrase of the target language with a narrower meaning.

Generalization is a transformation opposite to concretization; that is a replacement of a unit of the source language, which has a narrower meaning, with the unit of the target language with a broader meaning.

Syntactic adaptation (literal translation) is a grammatical transformation in which the syntactic structure of the source language is converted to a similar structure in the target language.

Grammatical substitution is a grammatical transformation due to which a grammatical unit in the source language is transformed into a unit of the target language with a different grammatical meaning, for example, substitution of parts of speech.

Sentence fragmentation/partitioning is a grammatical transformation according to which the syntactic structure of the sentence in the original language is transformed into two or more predicate structures of the target language.

Explication or descriptive translation is a lexicogrammatical transformation in which a lexical unit of the source language is replaced with a word combination that expresses its meaning, i.e. gives a more or less complete explanation or definition of this meaning in the target language.

Antonymic translation is a lexical- grammatical transformation in which the affirmative form in the source language is replaced by a negative form in the translation or, vice versa, a negative form by an affirmative one.

This is accompanied by a replacement of a lexical unit of the source language with a unit of the target language with an opposite meaning.

Compensation is a type of translation transformation, in which the elements of meaning that are lost in the translation from the source language into the target one are rendered in the text of the translation by some other means, and not necessarily in the same place of the text as in the original. This fills in, "compensates" for the lost meaning and, on the whole, the content of the original is reproduced more fully. It is not uncommon for grammatical means of the original to be replaced by lexical means and vice versa [28].

From the short review above, this traditional approach introduced by V.N. Komissarov can be applied to Chinese translation studies.

So, in this part we will address to grammatical transformations. Sentence fragmentation or partitioning of a sentence.

我方希望上述发价会引起贵方兴趣。望回复。一 We hope that this offer will be interesting for you and you will answer it. Here sentence fragmentation or partitioning of a sentence is used.

In Chinese the phrase "we look forward to hearing from you" is expressed by formal phrase and is written at the end of the letter-望回复.It means to get an answer. The Russian language prefers complex sentences, that's why two sentences in Chinese were integrated into one during the process of translation.

\section{Transposition.}

请立即以航邮将样品寄来。-Please send the samples by airmail as soon as possible. There is a direct word ordering Chinese, so the object is governed by the verbs. It is placed after the verb. In this case, according to the norms of the Chinese language, the use of the complex verb "to send" 寄来 requires the inversion of the direct object "samples" 样品, that's why the preposition 将 puts a direct object into the anteposition.

\section{Replacement.}

为了达到某些目的奉承别人。-To achieve certain goals to please others.

The verb 达到 《achieve» is changed into nominalization «achievement». Such transformation very often leads to manipulative effect [29].

\section{Addition.}

回信时望注明此文编号。- When responding, please refer to the number of this document. More often such transformation is used in translating from Russian into Chinese. Word-for-word translation of this sentences - In the response letter, we hope, you will specify this number. Laconic Chinese syntax needs more words in the process of translation into Russian. 


\section{Omission. 希望尽快收到上述材料，相信能与贵公}

司进行互利互惠交易。-We hope to receive the above materials as soon as possible, and conclude a mutually beneficial deal with you.

This transformation is mostly used in translation from Chinese into Russian. It helps to avoid tautology that can lead to stylistic mistakes. The word «hope» is expressed by two words 希望 and 相信. In the Russian sentence it is used only once.

Now let's discuss lexical transformations.

Concretization.

最好你把垃圾弄到郊外去。-It will be better if you take the garbage out of the city.

The word "take out" is transferred with a help of a verb 弄 which means “do". So, “do" is replaced by a word or phrase of the target language with a narrower meaning.

Generalization

话说那海焰进去得有三四个时辰了，却是悄无声

息。- Several hours had passed since Hai Yan entered, but there was no sound from inside.

In this example, the time period is rendered by means of the Chinese numerals "three and four" 三四, in translation it is appropriate to replace it with a word with the generalized meaning "several".

Antonymic translation.

您别急, 什么事情也不会发生 - Try to calm down, everything will be ok!

In the first part of the sentence the word with the positive connotation "calm down" is used instead of the literal “don't worry” 别急 in the target language. There are no negative pronouns in Chinese, so the interrogative pronoun "what" is used instead of the Russian "nothing" for the categorical negation.

Modulation.

蒙古族同胞称春节为《白节》, 正月叫《白月》。 - The small national groups of Mongolian origin living in the People's Republic of China call the New Year's Day "white holiday" and the first month of the lunar calendar (January) "white month".

Proceeding from the pragmatic purpose, in the target language it is necessary to take into account that Russian readers may not know the phrase "Spring Festival", so it should be called New Year. We should also explain why the Mongolians here are called a small nation, and the last explanation is about the first month of the lunar calendar, which in the Russian tradition is called January.

\section{Conclusion}

Hence, the present findings confirm that V.N. Komissarov's classification of transformations can be applied to the Chinese language. Moreover, such universal approach will help students in writing thesis papers. Due to understanding grammatical and lexical asymmetry of both languages this structured clear classification can help studying lexical and grammatical problems of translation from Russian into English and vice versa at a much deeper level.

\section{References}

1. M.V. Sofronov, The Chinese language and Chinese script. Course of lectures, 638 (2007)

2. L.G. Abdrahimov, L.A. Radus, V.V. Tkachuk, Military topics in Chinese proverbs and sayings, 120 (2014)

3. I.V. Voitsehovitch, A.F. Kondrashevskiy, The Chinese language: socio-political translation. Beginner's Course, 325 (2002)

4. I.V. Voitsehovitch, A.F. Kondrashevskiy, A.A.Voitsehovitch, Additional material for the textbook "The Chinese language: socio-political translation. Beginner's Course”, 152 (2017)

5. I.D. Klenin, V.F. Shichko, Lexicology of the Chinese language, 272 (2013)

6. A.V. Ankin, I.G. Khripunov, A practical course of translation (military translation). The Chinese language, 588 (2009)

7. A.V. Boyarkina, V.I.Voronov, K.S.Knyazeva, Methods of translation of military-political terms from the Chinese language into Russian / International Journal of Humanities and Natural Sciences, 8, 119-123 (2018)

8. R.A. Polonchuk, The Results of a comparative analysis translation of military phraseology in Chinese and Russian / Military-Humanitarian Almanac. Series "Linguistics", 1, 536-540 (2017)

9. K.V. Volkov, Linguotypological and linguoculturological features of the Chinese and Russian languages, Adjunct Bulletin, 2 (4), 1-21 (2019)

10. V.V. Kruglov, Problems of translation Xi Jinping's political speeches and syntactic features of using Chengyu of I Chingtradition / Modern Science: Actual Problems of Theory and Practice. Series "Humanities", 10 (2), 76-83 (2020)

11. E.A. Khamaeva, T. E. Shishmareva, E. V. Kremnyov, Translinguographic translation as a method of the expert translation (basing on the translations of "Shan Hai Jing" and "Erya") / CredeExperto: transport, society, education, language, 4 (07), 69-79 (2016)

12. O.M. Gotlib, M.I. Varakina, Translation of Mass Media, 127 (1997)

13. O.M. Gotlib, Business correspondence. RussianChinese equivalents, 254 (2012)

14. Yu. G. Lemeshko, The language of Chinese social and political text (syntactical and stylistic features), URL:https://rusneb.ru/catalog/000199_000009_0022 89790/ (date of access September 27, 2021)

15. Yu. G. Lemeshko, Chinese socio-political text. Stylistic peculiarities, 44 (2002) 
16. V.A. Rostovtsev, The theory of the Chinese language translation, 201 (1977)

17. V.F. Schichko, The theory of translation, 224 (2010)

18. V. F. Schichko, G.Yu. Yakovlev, A complete course of translation in 2 parts, 368 (2009)

19. N.V. Shchurik Journal of Siberian Fed. Univ. Hum. and social sciences 10, 591-597 (2017)

20. L.S. Barhudarov, Language and Translation (Moscow, Mezhdunarodnye Otnosheniya, 1975) 21. Ya.I. Retsker, Translation theory and practice of translation (1974)

22. A.D. Schweitzer, Theory of translation: Status, issues, aspects

(1988) 23. L.K. Latyshev, Course of translation. The equivalence of the translation and how to achieve it
(1981)

24. L.K.Latyshev, The semantic and syntactic problems in the theory of language and translation (1986). 25. T.A. Kazakova, Practical basics of translation. (Translation Techniques. English Russian) (2002) 26. V.G. Gak \& E. B. Roisenblit, (1965). Analytical review of French and Russian comparative language studies (1965) 27. N. K. Garbovsky, Theory of translation (2004) 28. V.N. Komissarov, General Theory of Translation: Problems of Translatology in the Works by Foreign Authors (Moscow, CheRo: Urait, 2000) 29. A.M. Kaplunenko, T.V. Tyurneva, T.I. Vedernikkova, N.V. Shchurik, Peoples Friendship Univ. of Russia, 11-118 (2020) 